\title{
All-oxide-semiconductor-based Thin-film Complementary Static Random Access Memory
}

DOI:

10.1109/LED.2018.2877589

\section{Document Version}

Accepted author manuscript

Link to publication record in Manchester Research Explorer

\section{Citation for published version (APA):}

Jin, Y., Yuan, Y., Yunpeng Li, Du, L., Wang, Y., Hu, Z., Qingpu Wang, Zhou, L., Qian Xin, \& Song, A. (2018). Alloxide-semiconductor-based Thin-film Complementary Static Random Access Memory. IEEE Electron Device Letters, 39(12), 1876-1879. https://doi.org/10.1109/LED.2018.2877589

\section{Published in:}

IEEE Electron Device Letters

\section{Citing this paper}

Please note that where the full-text provided on Manchester Research Explorer is the Author Accepted Manuscript or Proof version this may differ from the final Published version. If citing, it is advised that you check and use the publisher's definitive version.

\section{General rights}

Copyright and moral rights for the publications made accessible in the Research Explorer are retained by the authors and/or other copyright owners and it is a condition of accessing publications that users recognise and abide by the legal requirements associated with these rights.

\section{Takedown policy}

If you believe that this document breaches copyright please refer to the University of Manchester's Takedown Procedures [http://man.ac.uk/04Y6Bo] or contact uml.scholarlycommunications@manchester.ac.uk providing relevant details, so we can investigate your claim.

\section{OPEN ACCESS}




\section{- IEEE}

\section{All-oxide-semiconductor-based Thin-film Complementary Static Random Access Memory}

\begin{tabular}{|r|l|}
\hline Journal: & Electron Device Letters \\
\hline Manuscript ID & EDL-2018-08-1482 \\
\hline Dstype: & Letters \\
\hline Complete List of Authors: & $\begin{array}{l}\text { Yang, Jin; Shandong University, } \\
\text { Yuan, Yuzhuo; Shandong University, Centre of Nanoelectronics } \\
\text { Li, Yunpeng; Shandong University, Center of Nanoelectronics, State Key } \\
\text { Laboratory of Crystal Materials, and School of Microelectronics } \\
\text { Du, Lulu } \\
\text { Wang, Yiming; Shandong University, School of Microelectronics } \\
\text { Hu, Zhenjia } \\
\text { Wang, Qingpu; Shandong University, School of Microelectronics } \\
\text { Zhou, Li } \\
\text { Xin, Qian; Shandong University, School of Microelectronics } \\
\text { Song, Aimin; University of Manchester, Electrical and Electronic } \\
\text { Engineering; }\end{array}$ \\
\hline Keyword: & $\begin{array}{l}\text { Static random access memory (SRAM), complementary inverter, indium } \\
\text { gallium zinc oxide (InGaZnO or IGZO), tin monoxide (SnO), thin-film } \\
\text { transistor (TFT) }\end{array}$ \\
\hline
\end{tabular}




\title{
All-oxide-semiconductor-based Thin-film Complementary Static Random Access Memory
}

\author{
Jin Yang, Yuzhuo Yuan, Yunpeng Li, Lulu Du, Yiming Wang, Zhenjia Hu, Qingpu Wang, Li Zhou, \\ Qian Xin, and Aimin Song, Senior Member, IEEE
}

\begin{abstract}
Static random access memory (SRAM) is essential for cache memory. Although oxide semiconductors are ideal candidate materials for next generation flexible electronics, complementary SRAM based on oxide semiconductors has not yet been demonstrated. Here, we reported an SRAM with a traditional 6-transistor structure based on n-type indium gallium zinc oxide and p-type tin monoxide. A cell area of only $130 \times 160$ $\mu \mathrm{m}^{2}$ has been achieved, and is the smallest among the reported values of SRAMs based on flexible semiconductors. Both traditional static voltage characteristic and $\mathrm{N}$-curve methods are applied to analyse the noise margin level of the cell. The former method demonstrates a high noise margin of $1.43 \mathrm{~V}$ in read at $V_{D D}$ of $8 \mathrm{~V}$, and the latter demonstrates static current and voltage noise margins of $13 \mu \mathrm{A}$ and $2.05 \mathrm{~V}$, respectively. In addition, the SRAM cell shows rather short writing time of 121 and $82 \mu$ s for high and low writing states, respectively. This high performance complementary SRAM based on all oxide semiconductors indicates its high application potential in large-scale flexible electronics for data storage and processing.
\end{abstract}

Index Terms -Static random access memory (SRAM), complementary inverter, indium gallium zinc oxide (InGaZnO or IGZO), tin monoxide (SnO), thin-film transistor (TFT).

\section{INTRODUCTION}

$\mathrm{T}$ HI N-FILM technology is essential for integrated circuits with high volume, high functionality, low cost, and flexibility. Oxide semiconductors are ideal candidate materials for flexible circuits due to their unique advantages of high carrier mobility $\left(\sim 1-100 \mathrm{~cm}^{2} / \mathrm{Vs}\right)$, visible light transparency, and large-area and low-temperature processability. Recently, indium gallium zinc oxide ( $\mathrm{InGaZnO}$ or IGZO) thin-film

This work was financed by the National Key Research and Development Program of China (Grant Nos. 2016YFA0301200 and 2016YFA0201800), the National Natural Science Foundation of China (Grant No. 11374185), Engineering and Physical Sciences Research Council (EPSRC) (Grant No. EP/N021258/1), China Postdoctoral Science Foundation funded project (2016M590634), the Key Research and Development Program of Shandong Province (2017GGX10111 and 2017GGX10121), the Natural Science Foundation of Jiangsu Province (BK20151255), Suzhou Planning Projects of Science and Technology (SYG201527 and SYG201616), and the Fundamental Research Funds of Shandong University (2016WLJH44). (Corresponding author: Qian Xin; Li Zhou.)

J. Yang, Y. Yuan, Y. Li, L. Du, Y. Wang, Z. Hu, Q. Wang, L. Zhou, Q. Xin and A. Song are with the Centre of Nanoelectronics, State Key Laboratory of Crystal Materials, and School of Microelectronics, Shandong University, Jinan 250100, China (e-mail: xinq@sdu.edu.cn; lillysdu@qq.com).

J. Yang, Y. Yuan, Y. Li, L. Du, and Q. Xin are with the Suzhou Institute of Shandong University, Suzhou 215123, China.

A. Song is with the School of Electrical and Electronic Engineering, University of Manchester, Manchester M13 9PL, UK transistor (TFT) operating beyond $1 \mathrm{GHz}$ and flexible IGZO Schottky diode operating beyond $2.45 \mathrm{GHz}$ have been reported $[1,2]$. Radio frequency identification (RFID) tags and near field communication (NFC) technology, two important communicate interfaces in body-terminal network area of the internet of things (IoT), the next big wave in electronics [3], have been developed with IGZO TFT technology. However, all these reported thin-film tags read data from local read-only memories (ROMs) [4-6]. The data stored in ROMs can only be read but cannot be modified during operation, and thus restricting the storage capabilities, such as information update, which are highly desirable in IoT technology. In contrast to ROMs, static random access memories (SRAMs) can operate with both read and write modes, and are widely applied in cache memories, microprocessors, and systems-on-chip ( $\mathrm{SoC}$ ). Very recently, Myny et al. demonstrated an 8-bit organic thin-film microprocessor without SRAM, and accordingly, it cannot store either processor instruction or data [7]. Shulaker et al. reported the first computer built on 178 carbon nanotube TFTs with an external off-chip memory to realize signal reading and writing [8], and such external memory leads to reduced integration, enhanced power consumption, and increased area footprint.

Recently, to realize data storage and processing in future flexible electronics, several SRAMs based on flexible semiconductors have been demonstrated [3, 9-12]. Fukuda et al. fabricated an SRAM based on unipolar p-type organic TFTs, with a large cell area of $21 \mathrm{~mm}^{2}$ and a low write speed of $1.5 \mathrm{~ms}$ [10]. De Roose et al. demonstrated an 128-bit SRAM based on unipolar n-type IGZO TFTs [3]. In contrast to complementary SRAM, SRAM based on unipolar TFTs generally has a conflict between its performance and layout area. Geier et al. reported a complementary SRAM cell with very low power consumption based on carbon nanotube TFTs [11], but the high purity and large area homogeneity are still big challenge.

Due to the challenge of high performance p-type oxides, complementary SRAM based on both $\mathrm{p}$ - and n-type oxides has not yet been demonstrated. In this work, a high performance SRAM cell is fabricated with traditional 6-transistor structure based on n-type IGZO and p-type tin monoxide $(\mathrm{SnO})$ via a low-temperature process, which is suitable for large-scale and flexible fabrications. Its static performance is analysed by both static voltage characteristics and $\mathrm{N}$-curve which is commonly used for silicon SRAMs, and the results are in good agreement. The write speed was extracted from the dynamic waveforms. 


\section{EXPERIMENTAL}

N-type IGZO TFTs and p-type SnO TFTs with bottom-gate top-contact structure, and the SRAM cell with a structure shown in Fig. 1 were fabricated. Ti $(5 \mathrm{~nm})$ and $\mathrm{Au}(30 \mathrm{~nm})$ as the gate electrode were deposited by electron-beam evaporation on clean $\mathrm{Si}$ wafer substrate [13]. A 30-nm-thick $\mathrm{Al}_{2} \mathrm{O}_{3}$ layer was then deposited as the gate dielectric by atomic-layer deposition. A 20-nm-thick p-type SnO layer was deposited [13], and post-annealed in ambient air at $225^{\circ} \mathrm{C}$ for 2 hours. A 24-nm-thick n-type IGZO layer was then deposited by RF magnetron sputtering at room temperature [14]. Ti $(50 \mathrm{~nm})$ and $\mathrm{Au}(30 \mathrm{~nm})$ were deposited as source/drain contacts by electron-beam evaporation. Finally, the sample was annealed at $100^{\circ} \mathrm{C}$ for 1 hour in ambient air. The electrode and channel layers were patterned by UV lithography and lift off. The $\mathrm{Al}_{2} \mathrm{O}_{3}$ layer was patterned by UV lithography and inductively coupled plasma reactive ion etching. The electrical characteristics of the TFTs and SRAM cell were measured using a source/measure unit (Agilent B2902A) and oscilloscope (Keysight MSOX6004A) in the dark at room temperature.

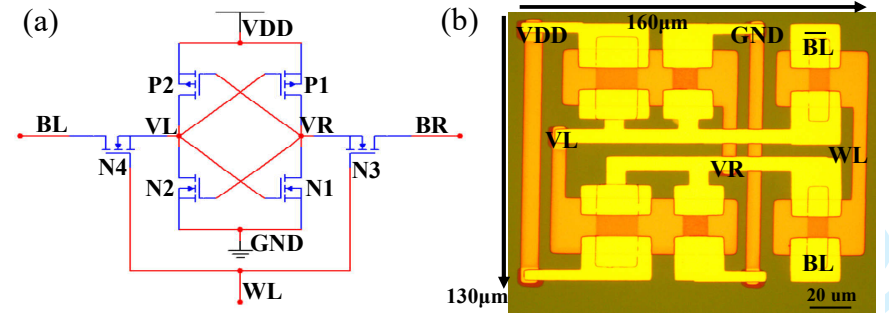

Fig. 1. Circuit diagram (a) and optical microscopy image (b) of the SRAM cell. All TFTs have a channel length $L$ of $10 \mu \mathrm{m}$; the channel width is $10 \mu \mathrm{m}$ for the access TFTs (N3 and N4) and pull-up TFTs (P1 and P2) and $20 \mu \mathrm{m}$ for the pull-down TFTs (N1 and N2). VR, VL, BR, BL, and WL are voltage nodes.

TABLE I

AREA OF REPORTED SRAM CELLS BASED ON FLEXIBLE SEMICONDUCTORS

\begin{tabular}{|c|c|c|c|c|c|c|}
\hline & $\begin{array}{c}2007 \\
{[9]}\end{array}$ & $\begin{array}{l}2011 \\
{[10]}\end{array}$ & $\begin{array}{l}2015 \\
{[11]} \\
\end{array}$ & $\begin{array}{l}2016 \\
{[12]} \\
\end{array}$ & $\begin{array}{c}2017 \\
{[3]}\end{array}$ & $\begin{array}{c}\text { Our } \\
\text { work }\end{array}$ \\
\hline Materials & Organic & Organic & CNT & Organic & IGZO & $\begin{array}{c}\text { IGZO } \\
\text { SnO }\end{array}$ \\
\hline $\operatorname{Area}\left(\mathrm{mm}^{2}\right)$ & 7.4 & 21 & 0.6 & $>1$ & 0.0276 & 0.0208 \\
\hline $\begin{array}{c}\text { Write } \\
\text { “1”/“0”(us) }\end{array}$ & & $1500 / 300$ & - & $300 / 500$ & $110 / 110$ & $121 / 82$ \\
\hline $\mathrm{RSNM}(\mathrm{V})$ & 6.2 & 0.44 & 0.32 & 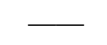 & 2.37 & 1.43 \\
\hline WSNM(V) & $\overline{ }$ & - & 0.37 & 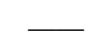 & 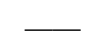 & 1.67 \\
\hline $\mathrm{V}_{\mathrm{DD}}(\mathrm{V})$ & 40 & 2 & 1.25 & 40 & 15 & 8 \\
\hline
\end{tabular}

\section{RESULTS AND DISCUSSION}

Figure 1(a) presents the circuit diagram of the complementary SRAM cell with optimised size. The SRAM composed by two cross-coupled complementary inverters and two access n-type TFTs. In an ideal case, the two inverters should have infinite gains [15], and recently we have realized oxide semiconductor inverters with a record high gain [13]. The cell area remains one of the key parameters for SRAM design in terms of cost and volume. The SRAM cell has an area of 0.0208 $\mathrm{mm}^{2}$, which is, to the best of our knowledge, the smallest area among the reported SRAMs based on flexible semiconductors to date, as shown in Fig. 1(b). The transfer and output characteristics of the n-type IGZO and p-type SnO TFTs are shown in Fig. 2. The carrier mobility, subthreshold swing $(S S)$,
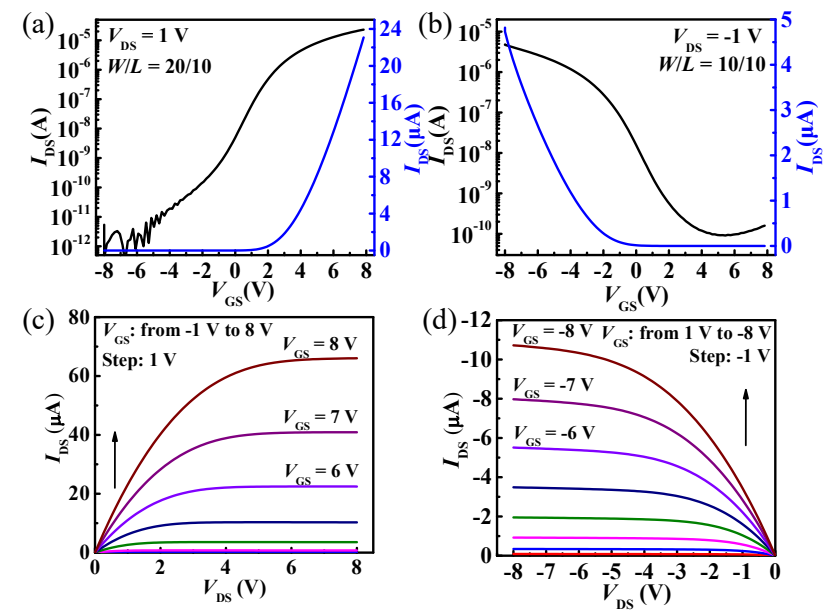

Fig. 2. (a)(b) Transfer and (c)(d) output characteristics of the n-type IGZO TFT and the p-type SnO TFT, respectively.
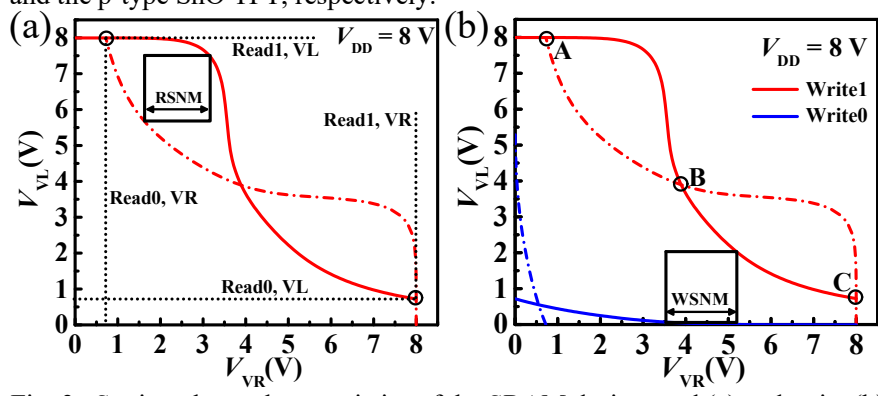

Fig. 3. Static voltage characteristics of the SRAM during read (a) and write (b) operations. The solid curves are measured, and the dash curves are mirrored with respect to a line passing through the origin at $45^{\circ}$ from the horizontal. threshold voltage $\left(V_{\mathrm{TH}}\right)$, and on/off current ratio of the IGZO and SnO TFTs are 10.3 and $1.1 \mathrm{~cm}^{2} \mathrm{~V}^{-1} \mathrm{~s}^{-1}, 0.8$ and $1.3 \mathrm{~V} / \mathrm{dec}$, 3.1 and $-2.8 \mathrm{~V}$, and $6 \times 10^{6}$ and $2.6 \times 10^{4}$, respectively.

The cell stability determines the soft-error rate and the sensitivity of the memory [16]. The read stability is graphically analysed by the read static noise margin (RSNM), as shown in Fig. 3(a). To characterise the RSNM, the BL and BR voltages were clamped at $V_{\mathrm{DD}}$ of $8 \mathrm{~V}$, and the word-line (WL) was activated to allow stored data to be transferred. A voltage sweep from $0 \mathrm{~V}$ to $V_{\mathrm{DD}}$ was applied at $\mathrm{VR}$, and $\mathrm{VL}$ voltage was measured. The measured curve and mirror curve are shown in Fig. 3(a), and the RSNM value is $1.43 \mathrm{~V}$, equalling to the side length of the inserted square. The write-ability is graphically analysed by the write static noise margin (WSNM). As shown in Fig. 3(b), the red curve corresponds to writing data " 1 " under a high BR voltage of $8 \mathrm{~V}$ while the blue curve corresponds to writing data " 0 " under a low BR voltage of $0 \mathrm{~V}$. The value of WSNM $1.67 \mathrm{~V}$ equals to the side length of the square between the two static voltage characteristics. The pull-up TFT P1 is weaker than the access TFT N3 due to higher channel resistance, and this lead to a strong write capability during a write operation. However, a strong read capability requires a stronger pull-down TFT N2 than access TFT N4. Hence, with $(W / L)_{\mathrm{N} 2} /(W / L)_{\mathrm{N} 4}=2$, high and balanced RSNM and WSNM values are realized with the smallest area, as shown in Table 1.

The above method of measuring static voltage characteristics has two drawbacks. One is the inability to measure it with automatic inline testers [17], and the other is the limitation of supply voltage scaling for static noise margin [15]. Here, we applied an alternative $\mathrm{N}$-curve method [17] which is commonly 


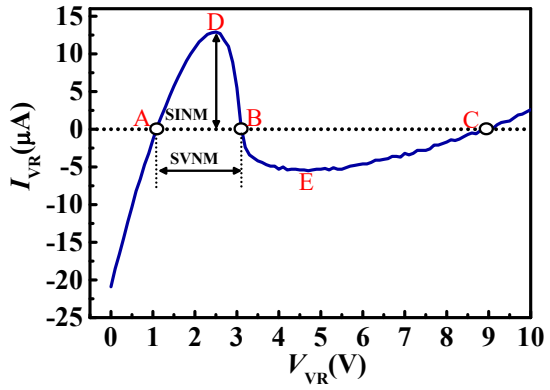

Fig. 4. N-curve of the SRAM cell.
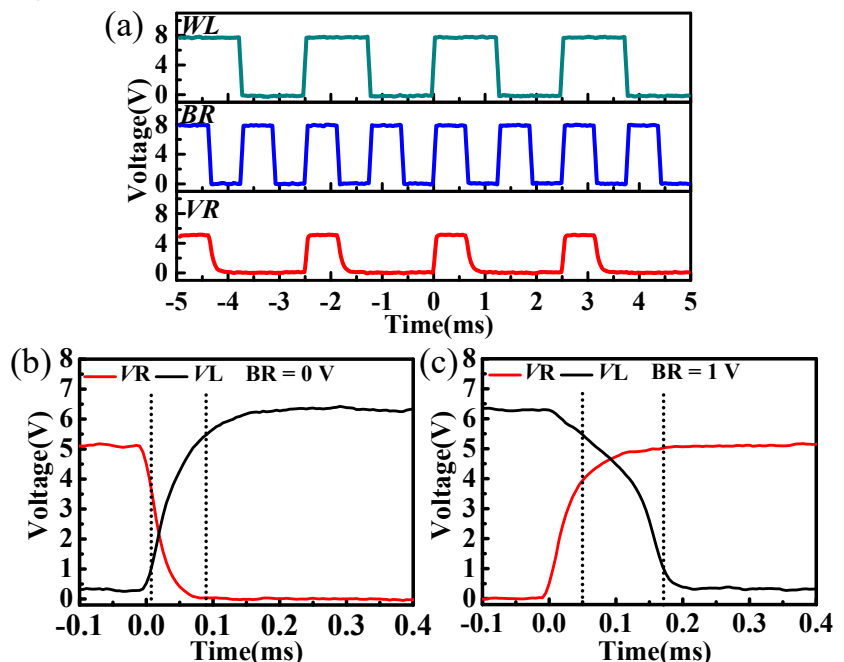

Fig. 5. (a) Response of the SRAM cell when WL is enabled and disabled. VR and VL waveforms during write operation with (b) low and (c) high BR signals. used for silicon based SRAMs but has not yet been used in other flexible semiconductors based SRAMs. For obtaining $\mathrm{N}$-curve as shown in Fig. 4, the WL, BL, and BR voltages were set at $V_{\mathrm{DD}}$ of $8 \mathrm{~V}$, and then a voltage sweep from $0 \mathrm{~V}$ to $V_{\mathrm{DD}}$ was applied at VR, and the corresponding current, $I_{\mathrm{VR}}$, was measured. The voltage difference between point $\mathrm{A}$ and $\mathrm{B}$ is the static voltage noise margin (SVNM), indicating the maximum DC noise voltage at VR. The peak current at point $\mathrm{D}$ between point $A$ and $B$ is the static current noise margin (SINM), which is the maximum DC current that can be injected at VR. Not only voltage but also current information can be extracted from this N-curve. The extracted values of SVNM and SINM are $2.05 \mathrm{~V}$ and $13 \mu \mathrm{A}$, respectively. In addition, the N-curve and static voltage characteristic are closely associated. The A and $\mathrm{C}$ points in N-curve correspond to the stable points $\mathrm{A}$ and $\mathrm{C}$ in Fig. 3 (b), while point $\mathrm{B}$ in $\mathrm{N}$-curve corresponds to meta-stable point $\mathrm{B}$ in Fig. 3(b). The voltage values at A, B, and C in N-curve of $1.07,3.12$, and $8.9 \mathrm{~V}$, agree well with the corresponding values of 0.7, 3.9, and $8 \mathrm{~V}$ in Fig. 3(b).

The dynamic response of the SRAM cell was measured when WL was enabled and disabled, as shown in Fig. 5(a). The VR voltage is less than $V_{\mathrm{DD}}$, and this is mainly because that only n-type TFT acting as transmission gate, a $V_{\mathrm{TH}}$ is consumed when signal passes. The write time, namely transition time, defined as the time required to transition between $10 \%$ and $90 \%$ of the amplitude, is also a key parameter which determines the data storage speed. Figure 5(b) and (c) shows the waveforms measured at the VR and VL nodes during a write operation. The transition time at VL node is 82 and $121 \mu$ s when the low state
"0" and high state "1" were written into the cell, respectively. This is, to the best of our knowledge, the fastest writing speed among the reported values [3], [10], [12], as shown in Table 1.

\section{CONCLUSION}

In this work, we have reported a complementary SRAM based on all oxide semiconductors for the first time. The low processing-temperature $\left(\leq 225{ }^{\circ} \mathrm{C}\right)$ indicates that the whole process is possibly transferred to flexible substrate. Both high performance and the smallest area of $0.0208 \mathrm{~mm}^{2}$ compared with other flexible semiconductors based SRAMs have been realized. High noise margins of the SRAM have been confirmed by both traditional static voltage characteristic and $\mathrm{N}$-curve methods. The SRAM exhibits, to the best of our knowledge, the fastest write speed of 82 and $121 \mu$ s among the flexible semiconductors based SRAMs when writing "0" and "1", respectively. Our results indicate that the SRAM satisfies well the urgent requirements of data storage and processing in large-scale flexible and/or transparent integrated circuits.

\section{REFERENCES}

[1] Y. Wang, J. Yang, H. Wang, J. Zhang, H. Li, G. Zhu, Y. Shi, Y. Li, Q. Wang, Q. Xin, Z. Fan, F. Yang, and A. Song, "Amorphous-InGaZnO Thin-Film Transistors Operating Beyond $1 \mathrm{GHz}$ Achieved by Optimizing the Channel and Gate Dimensions," IEEE Transactions on Electron Devices, pp. 1-6, Mar. 2018, doi:10.1109/ted.2018.2807621.

[2] J. Zhang, Y. Li, B. Zhang, H. Wang, Q. Xin, and A. Song, "Flexible indium-gallium-zinc-oxide Schottky diode operating beyond $2.45 \mathrm{GHz}$," Nat Commun, vol. 6, pp. 7561, Jul. 2015, doi:10.1038/ncomms8561.

[3] F. De Roose, K. Myny, M. Ameys, J.-L. P. J. van der Steen, J. Maas, J. de Riet, J. Genoe, and W. Dehaene, "A Thin-Film, a-IGZO, 128b SRAM and LPROM Matrix With Integrated Periphery on Flexible Foil," IEEE Journal of Solid-State Circuits, vol. 52, no. 11, pp. 3095-3103, Aug. 2017, doi:10.1109/jssc.2017.2731808.

[4] B.-D. Yang, "A Transparent Logic Circuit for RFID Tag in a-IGZO TFT Technology," ETRI Journal, vol. 35, no. 4, pp. 610-616, Aug. 2013, doi:10.4218/etrij.13.1912.0004.

[5] K. Myny, Y.-C. Lai, N. Papadopoulos, F. De Roose, M. Ameys, M. Willegems, S. Smout, S. Steudel, W. Dehaene, and J. Genoe, "15.2 A flexible ISO14443-A compliant 7.5mW 128b metal-oxide NFC barcode tag with direct clock division circuit from $13.56 \mathrm{MHz}$ carrier," in Proc. IEEE ISSCC, San Francisco, CA, USA, Mar. 2017, pp. 258-259, doi:10.1109/isscc.2017.7870359.

[6] H. Ming-Hao, C. Chung-Hung, L. Yi-Cheng, T. Kuan-Wen, L. Wei-Ting, W. Hsiu-Hua, C. Feng-Jui, C. Chun-Cheng, C. Chin-Tang, H. Yu-Sheng, Y. Cheng-Nan, L. Chu-Yu, T. Jen-Pei, C. Min-Feng, and L. Yu-Chieh, "Ultra low voltage 1-V RFID tag implement in a-IGZO TFT technology on plastic," in Proc. IEEE RFID, Phoenix, AZ, USA, Jun. 2017, pp. 193-197, doi:10.1109/rfid.2017.7945608.

[7] K. Myny, E. van Veenendaal, G. H. Gelinck, J. Genoe, W. Dehaene, and P. Heremans, "An 8-Bit, 40-Instructions-Per-Second Organic Microprocessor on Plastic Foil," IEEE Journal of Solid-State Circuits, vol. 47, no. 1, pp. 284-291, Nov. 2012, doi:10.1109/jssc.2011.2170635.

[8] M. M. Shulaker, G. Hills, N. Patil, H. Wei, H. Y. Chen, H. S. Wong, and S. Mitra, "Carbon nanotube computer," Nature, vol. 501, no. 7468, pp. 526-30, Sep. 2013, doi:10.1038/nature12502.

[9] M. Takamiya, T. Sekitani, Y. Kato, H. Kawaguchi, T. Someya, and T. Sakurai, "An Organic FET SRAM With Back Gate to Increase Static Noise Margin and Its Application to Braille Sheet Display," IEEE Journal of Solid-State Circuits, vol. 42, no. 1, pp. 93-100, Dec. 2007, doi: $10.1109 /$ jssc. 2006.886578 .

[10] K. Fukuda, T. Sekitani, U. Zschieschang, H. Klauk, K. Kuribara, T. Yokota, T. Sugino, K. Asaka, M. Ikeda, H. Kuwabara, T. Yamamoto, K. Takimiya, T. Fukushima, T. Aida, M. Takamiya, T. Sakurai, and T. Someya, "A 4 V Operation, Flexible Braille Display Using Organic Transistors, Carbon Nanotube Actuators, and Organic Static 
Random-Access Memory," Advanced Functional Materials, vol. 21, no. 21, pp. 4019-4027, Sep. 2011, doi:10.1002/adfm.201101050.

[11] M. L. Geier, J. J. McMorrow, W. Xu, J. Zhu, C. H. Kim, T. J. Marks, and M. C. Hersam, "Solution-processed carbon nanotube thin-film complementary static random access memory," Nat Nanotechnol, vol. 10, no. 11, pp. 944-8, Sep. 2015, doi:10.1038/nnano.2015.197.

[12] J. A. Avila-Niño, E. R. Patchett, D. M. Taylor, H. E. Assender, S. G. Yeates, Z. Ding, and J. J. Morrison, "Stable organic static random access memory from a roll-to-roll compatible vacuum evaporation process," Organic Electronics, vol. 31, pp. 77-81, Apr. 2016, doi:10.1016/j.orgel.2016.01.017.

[13] J. Yang, Y. Wang, Y. Li, Y. Yuan, Z. Hu, P. Ma, L. Zhou, Q. Wang, A. Song, and Q. Xin, "Highly Optimized Complementary Inverters Based on p-SnO and n-InGaZnO With High Uniformity," IEEE Electron Device Letters, vol. 39, no. 4, pp. 516-519, Apr. 2018, doi:10.1109/led.2018.2809796.

[14] B. Zhang, H. Li, X. Zhang, Y. Luo, Q. Wang, and A. Song, "Performance regeneration of InGaZnO transistors with ultra-thin channels," Applied Physics Letters, vol. 106, no. 9, pp. 093506, Mar. 2015, doi:10.1063/1.4914296.

[15] E. Grossar, M. Stucchi, K. Maex, and W. Dehaene, "Read Stability and Write-Ability Analysis of SRAM Cells for Nanometer Technologies," IEEE Journal of Solid-State Circuits, vol. 41, no. 11, pp. 2577-2588, Oct. 2006, doi:10.1109/jssc.2006.883344.

[16] E. Seevinck, F. J. List, and J. Lohstroh, "Static-noise margin analysis of MOS SRAM cells," IEEE Journal of Solid-State Circuits, vol. 22, no. 5, pp. 748-754, Oct. 1987, doi:10.1109/jssc.1987.1052809.

[17] C. Wann, R. Wong, D. J. Frank, R. Mann, K. Shang-Bin, P. Croce, D. Lea, D. Hoyniak, L. Yoo-Mi, J. Toomey, M. Weybright, and J. Sudijono, "SRAM cell design for stability methodology," in Proc. IEEE VLSI-TSA-Tech, Hsinchu, Taiwan, Aug. 2005, pp. 21-22, doi:10.1109/vtsa.2005.1497065. 